OPEN ACCESS

Edited by:

Maria Do Carmo Pereira,

University of Porto, Portugal

Reviewed by:

Luigia Trabace,

University of Foggia, Italy

Bruno Pietro Imbimbo,

Chiesi Farmaceutici, Italy

*Correspondence:

Yu Yang

yang_yu@jlu.edu.cn

Xu Wang

xuwang@jlu.edu.cn

${ }^{+}$These authors have contributed equally to this work

Specialty section: This article was submitted to

Neuropharmacology,

a section of the journal

Frontiers in Pharmacology

Received: 16 January 2021 Accepted: 09 April 2021

Published: 22 April 2021

Citation:

Sun Z-T, Ma C, Li G-J, Zheng X-Y, Hao $Y$ - $T$, Yang $Y$ and Wang $X$ (2021)

Application of Antibody Fragments

Against $A \beta$ With Emphasis on

Combined Application With

Nanoparticles in Alzheimer's Disease.

Front. Pharmacol. 12:654611.

doi: 10.3389/fphar.2021.654611

\section{Application of Antibody Fragments Against $A \beta$ With Emphasis on Combined Application With Nanoparticles in Alzheimer's Disease}

\author{
Zhi-Ting Sun ${ }^{1 \dagger}$, Chi Ma ${ }^{2 \dagger}$, Guang-Jian $\mathrm{Li}^{1}$, Xiang-Yu Zheng ${ }^{1}$, Yi-Tong Hao ${ }^{1}, \mathrm{Yu} \mathrm{Yang}^{1 *}$ and \\ Xu Wang ${ }^{1 *}$
}

${ }^{1}$ Department of Neurology and Neuroscience Center, The First Hospital of Jilin University, Changchun, China, ${ }^{2}$ Department of Neurosurgery, The First Hospital of Jilin University, Changchun, China

Alzheimer's disease (AD) is one of the most common neurodegenerative diseases and accumulating evidences suggest a key role of amyloid- $\beta(A \beta)$ peptide in the pathogenesis of AD. According to the amyloid cascade hypothesis, the imbalance of producing and clearing $A \beta$ is the beginning of neurodegeneration and dementia. Consequently, immunotherapy becomes popular through using antibodies against $A \beta$. However, many studies of monoclonal antibodies were stopped because adverse effects appeared or there were no evident benefits observed. Some antibody fragments have many advantages over monoclonal antibodies, such as small sizes, lack of the crystallizable fraction $(F c)$ and so on. There are three main antibody fragments, including single chain variable fragments (scFvs), Fab fragments and single-domain antibody fragments. Nanoparticles can facilitate the entry of drug molecules across the blood-brain barrier, making them become excellent carriers. Various kinds of nanoparticles have been applied in the treatment of AD. The combination of nanoparticles and antibody fragments against amyloid- $\beta$ can be used in the diagnosis and treatment of Alzheimer's disease. In this review, we summarize the progress of antibody fragments against amyloid- $\beta$ in $A D$, focusing on the combined application with nanoparticles in the diagnosis and treatment of $A D$.

Keywords: antibody fragments, amyloid- $\beta$, nanoparticle, Alzheimer's disease, immunotherapy

\section{INTRODUCTION}

Alzheimer's disease (AD) is the most common cause of dementia (Holmes and Amin, 2020). One of the important pathological characteristics of $\mathrm{AD}$ is the extracellular aggregation of amyloid plaques, mostly consisted of amyloid- $\beta$ (A $\beta$ ) peptide. (Uddin et al., 2020). According to the amyloid cascade hypothesis, $A \beta$ plays a key role in the development of $\mathrm{AD}$ (Uddin et al., 2020). $\mathrm{A} \beta$ is accumulated because it is overproduced or there is deficiency in elimination (Uddin et al., 2020). The excess of $A \beta$ results in the aggregated fibrils and neurotoxic oligomers. Immunotherapy targeting $A \beta$ to promote the elimination of $\mathrm{A} \beta$ has become a promising strategy to treat $\mathrm{AD}$ (Behl et al., 2020). Bapineuzumab is a monoclonal antibody $(\mathrm{mAb})$ against $\mathrm{A} \beta$, which was terminated in phase 3 clinical trials (Loureiro et al., 2020). Many second generation of anti-amyloid mAbs have been studied and undergone clinical trials. However, lots of clinical trials were terminated because results were not successful (Tian Hui Kwan et al., 2020). These monoclonal antibodies that entered phase 3 clinical trials mainly include Crenezumab, Solanezumab, Gantenerumab and Aducanumab (Tian Hui Kwan et al., 2020). 
TABLE 1 | Antibody fragments against different epitopes of $A \beta$ in AD.

\begin{tabular}{|c|c|c|c|c|}
\hline Epitope & $\begin{array}{l}\text { Antibody } \\
\text { fragments }\end{array}$ & Investigation model & Comments & Reference \\
\hline \multirow[t]{8}{*}{$\begin{array}{l}N \text {-terminal } \\
\text { region of } A \beta\end{array}$} & ScFv-h3D6 & $\begin{array}{l}\text { SH-SY5Y cells } \\
\text { 3xTg-AD mice }\end{array}$ & $\begin{array}{l}\text { Inhibit amyloid fibril formation and cytotoxicity, } \\
\text { improve memory and learning abilities, decrease } \\
\text { levels of apoE, apoJ and tau, reduce levels of A } \beta \\
\text { oligomers and IL- } 6 \text {, increase volume of brain and } \\
\text { keep neurons within DCN from death, target } \\
\text { oligomers, monomers, fibrils }\end{array}$ & $\begin{array}{l}\text { Marin-Argany et al. (2011); Esquerda-Canals et al. } \\
\text { (2013); Gimenez-Llort et al. (2013); Roda et al. } \\
\text { (2020b); Guell-Bosch et al. (2020) }\end{array}$ \\
\hline & ScFv-IC16 & $\begin{array}{l}\text { 7PA2 cells } \\
\text { Tg2576 mice }\end{array}$ & $\begin{array}{l}\text { As a probe to detect } A \beta \text { aggregation, target } \\
\text { monomers, oligomers, fibrils }\end{array}$ & Dornieden et al. (2013) \\
\hline & ScFv HT7 & $\begin{array}{l}\text { SH-SY5Y cells, HUVEC and } \\
\text { C6 glioma cells }\end{array}$ & $\begin{array}{l}\text { Prevent aggregation of } A \beta \text {, decrease cytotoxicity } \\
\text { and transport the BBB with high efficiency, target } \\
\text { oligomers, protofibrils, fibrils }\end{array}$ & Zhang Y. et al. (2019) \\
\hline & ScFv9 & Drosophila & Improve memory impairment significantly & Martin-Pena et al. (2017) \\
\hline & A8 scFv & $\begin{array}{l}\text { A model of cell-free A } \beta \text { "on- } \\
\text { pathway" aggregation }\end{array}$ & $\begin{array}{l}\text { Prevent aggregation of } A \beta \text { and disaggregate } \\
\text { fibrils }\end{array}$ & Zhang et al. (2015c) \\
\hline & WO-2 Fab & neuroblastoma cells & $\begin{array}{l}\text { Inhibit the toxicity caused by } A \beta \text { oligomer and } \\
\text { aggregation, boost the disaggregation of } \\
\text { amyloid fibrils }\end{array}$ & Robert et al. (2010) \\
\hline & $\begin{array}{l}\mathrm{F}(\mathrm{ab}) \text { '2 fragment } \\
\text { of an IgG1 mAb }\end{array}$ & Tg2576 mice & Decrease $A \beta$ plaque formation & Tamura et al. (2005) \\
\hline & $\begin{array}{l}\text { Fab fragment of } \\
\text { NT4X }\end{array}$ & $\begin{array}{l}\text { Transgenic mice (Tg4-42 } \\
\text { mice and 5XFAD mice) }\end{array}$ & $\begin{array}{l}\text { Therapeutic effect on loss of neurons and } \\
\text { memory impairment }\end{array}$ & (Antonios et al., 2015) \\
\hline \multirow{4}{*}{$\begin{array}{l}\text { Central region } \\
\text { of } A \beta\end{array}$} & B4.4 & SH-SY5Y cells & Neutralize toxicity of $A \beta$ & Solorzano-Vargas et al. (2008) \\
\hline & H1v2 scFv & SH-SY5Y cells & Reduce $A \beta$ aggregation and eliminate toxicity & Liu et al. (2004) \\
\hline & 1E8 scFv & $\begin{array}{l}\text { PC12 cell line and murine } \\
\text { primary neurons }\end{array}$ & $\begin{array}{l}\text { Decrease formation of fibril and protect cells from } \\
\text { toxicity }\end{array}$ & Nisbet et al. (2013) \\
\hline & ScFv17 & APP/PS1 transgenic mice & Decrease pathological impairments & Hu et al. (2018) \\
\hline \multirow[t]{2}{*}{$\begin{array}{l}\text { C-terminal } \\
\text { region of } A \beta\end{array}$} & VHH V31-1 & $\begin{array}{l}\text { Amyloids from AD patient } \\
\text { brain tissue, SK-N-SH cells }\end{array}$ & Prevent toxicity and formation of fibrils & Lafaye et al. (2009) \\
\hline & ScFv42.2 & Drosophila & Improve memory deficit significantly & Martin-Pena et al. (2017) \\
\hline
\end{tabular}

BBB, blood-brain barrier; DCN, deep cerebellar nuclei; ScFv, single chain variable fragment.

These studies of Solanezumab and Crenezumab were terminated due to lack of efficacy. In terms of Gantenerumab and Aducanumab, although many studies were also terminated, there are researches still in progress (Tian Hui Kwan et al., 2020).

Some antibody fragments preserve the ability of combining with antigen, which can replace complete mAbs (Bitencourt et al., 2020). The size of antibody fragment is small, enhancing the capacity of passing through BBB. Besides, they can be very useful in imaging and the manufacturing cost is not high. There are three main kinds of antibody fragments, including single chain variable fragment $(\mathrm{scFv}), \mathrm{Fab}$ fragment and single-domain antibody fragment (Bitencourt et al., 2020). Applying antibody fragments and combining them with nanoparticles in the diagnosis and treatment of $\mathrm{AD}$ are mainly discussed in this review. These antibody fragments against different epitopes of $\mathrm{A} \beta$ in $\mathrm{AD}$ are summarized in Table 1 . And the antibody fragments against $A \beta$ oligomers are summarized in Table 2.

\section{THE APPLICATION OF ANTIBODY FRAGMENTS AGAINST A $\beta$ IN AD}

\section{The Application of scFvs Against $A \beta$ in AD}

Applying scFv is safer compared with using compete $\mathrm{mAb}$, because $s c F v$ do not contain the crystallizable fraction $(\mathrm{Fc})$, which activates microglia and triggers complement system
(Bitencourt et al., 2020). Therefore, Fc fragment is related to adverse effects produced by $\mathrm{mAb}$. These adverse effects were part of the reason of stopping the clinical trials of Bapineuzumab (Bitencourt et al., 2020). Another reason was that researchers did not obtain treatment effect. The beginning of the treatment with Bapineuzumab was late in the clinical trials, which had been considered to be a reason for not obtaining clinical benefits. Therefore, treating AD in a prodromal stage is necessary (Tian Hui Kwan et al., 2020).

These scFvs can target different linear epitopes of $\mathrm{A} \beta$, including $\mathrm{N}$-terminal region, central region and $\mathrm{C}$-terminal region. Besides, they can also target various conformational epitopes, which contain monomers, oligomers, protofibrils and fibrils (Robert and Wark, 2012).

\section{ScFvs Targeting the N-Terminal Region of $A \beta$ (Amino Acids 1-16) Experiments of scFvs Targeting the $N$-Terminal Region of $A \beta$} In Vitro

ScFv-h3D6 was obtained from Bapineuzumab (EsquerdaCanals et al., 2019b). It was proved to be able to inhibit cytotoxicity caused by $A \beta$ peptide in the SH-SY5Y neuroblastoma cell line. The formation of amyloid fibril was also prevented by it (Marin-Argany et al., 2011). The conformational mechanism was relevant to the worm-like pathway (Marin-Argany et al., 2011). As for producing 
TABLE 2 | Antibody fragments against $A \beta$ oligomers.

\begin{tabular}{|c|c|c|c|}
\hline $\begin{array}{l}\text { Antibody } \\
\text { fragments }\end{array}$ & Investigation model & Comments & Reference \\
\hline $\begin{array}{l}\text { W8 } \\
\text { W9 } \\
\text { W20 } \\
\text { WC2 }\end{array}$ & SH-SY5Y cells & Inhibit fibrillation of $A \beta$ and prevent cytotoxicity & Wang X.-p. et al. (2009) \\
\hline A4 scFv & $\begin{array}{l}\text { SH-SY } 5 Y \text { cells } \\
\text { Brain tissues of PD, AD and non disease } \\
\text { patients }\end{array}$ & Inhibit $A \beta$ aggregation and decrease the toxicity & Zameer et al. (2008) \\
\hline C6 & $\begin{array}{l}\text { 7PA2 cells (a CHO cell line that over- } \\
\text { expresses hAPP) wild type and triple } \\
\text { transgenic ( } 3 \times \mathrm{Tg} \text { ) mice }\end{array}$ & Combine with oligomeric $A \beta$ specifically & Kasturirangan et al. (2013) \\
\hline NUsc1 & $\begin{array}{l}\text { Hippocampal neurons } \\
\text { AD-transgenic mice and wild type mice }\end{array}$ & $\begin{array}{l}\text { Comebine with } A \beta \text { oligomers with high specificity, } \\
\text { decrease oxidative stress of neuron, and decrease } \\
\text { tau hyperphosphorylation }\end{array}$ & Sebollela et al. (2017) \\
\hline MO6 & SH-SY5Y cells, HUVEC and C6 glioma cells & $\begin{array}{l}\text { Cross the BBB, reduce cytotoxicity, and increase cell } \\
\text { viability }\end{array}$ & Zhang et al. (2015a) \\
\hline AS & $\begin{array}{l}\text { SH-SY5Y cells, HUVEC and C6 glioma cells, } \\
\text { rat primary neurons }\end{array}$ & $\begin{array}{l}\text { Pass through the BBB, prevent cytotoxicity, and } \\
\text { decrease the level of } A \beta\end{array}$ & Zhang et al. (2015b) \\
\hline ScFv-IC16 & $\begin{array}{l}\text { 7PA2 cells } \\
\text { Tg2576 mice }\end{array}$ & As a probe to detect $A \beta$, inhibit $A \beta$ aggregation & Dornieden et al. (2013) \\
\hline ScFv HT7 & SH-SY5Y cells, HUVEC and C6 glioma cells & $\begin{array}{l}\text { Prevent aggregation of } A \beta \text {, decrease cytotoxicity and } \\
\text { transport the BBB with high efficiency }\end{array}$ & Zhang Y. et al. (2019) \\
\hline scFv HT6 & SH-SY5Y cells & Prevent $A \beta$ aggregation and decrease cytotoxity & Zhang X. et al. (2019) \\
\hline $\begin{array}{l}\text { 10D5-scFv } \\
\text { 12B4-scFv }\end{array}$ & $\begin{array}{l}\text { Pheochromocytoma (PC12) cells } \\
\text { APPswe/PS1dE9 transgenic mice }\end{array}$ & $\begin{array}{l}\text { Prevent from forming oligomers and fibers of } A \beta \text { and } \\
\text { inhibit toxicity }\end{array}$ & Fu et al. (2020) \\
\hline ScFv-h3D6 & $\begin{array}{l}\text { SH-SY5Y cells } \\
\text { 3xTg-AD mice }\end{array}$ & $\begin{array}{l}\text { Inhibit formation of amyloid fibril, and protect cells } \\
\text { from toxicity, improve memory and learning abilities, } \\
\text { decrease levels of apoE, apoJ and tau, reduce levels } \\
\text { of } A \beta \text { oligomers and IL- } 6 \text {, increase volume of brain } \\
\text { and keep neurons within DCN from death }\end{array}$ & $\begin{array}{l}\text { Marin-Argany et al. (2011); Esquerda-Canals et al. } \\
\text { (2013); Gimenez-Llort et al. (2013); Roda et al. } \\
\text { (2020b); Guell-Bosch et al. (2020) }\end{array}$ \\
\hline VHH V31-1 & $\begin{array}{l}\text { Amyloids from AD patient brain tissue, SK-N- } \\
\mathrm{SH} \text { cells }\end{array}$ & Prevent toxicity and formation of fibrils & Lafaye et al. (2009) \\
\hline
\end{tabular}

BBB, blood-brain barrier; DCN, deep cerebellar nuclei; ScFv, single chain variable fragment.

scFv-h3D6, there are many problems in producing it from Escherichia coli, such as the existence of endotoxins. Therefore, producing it from Pichia pastoris was studied by Montoliu-Gaya et al. (2017a). In terms of inhibition of toxicity, they proved that effects of scFv-h3D6 were not changed whether it was obtained from Escherichia coli or from Pichia pastoris (Montoliu-Gaya et al., 2017a). The effect of inhibiting toxicity caused by A $\beta$ was evaluated in the SH-SY5Y neuroblastoma cell line. Besides, obtaining this antibody fragment from Pichia pastoris had more advantages than from Escherichia coli, which made Pichia pastoris a better choice for producing scFv-h3D6 (Montoliu-Gaya et al., 2017a). Montoliu-Gaya et al. (2017b) also found that the production yield could be increased by eliminating the disulfide bond of the $\mathrm{V}_{\mathrm{H}}$ domain, resulting in the absence of scrambling conformations (Montoliu-Gaya et al., 2017b).

ScFv-IC16 could identify different $A \beta$ species, including monomers, oligmers and protofibrils, which was confirmed by ELISA analysis (Dornieden et al., 2013). And scFv-IC16 was able to stain $\mathrm{A} \beta$ plaques in the brain slices of $\mathrm{AD}$ transgenic mice by immunohistochemistry. Therefore, scFv-IC16 could be used as a molecular probe of detecting $A \beta$, which was potential for diagnosing and treating AD (Dornieden et al., 2013). A8 scFv, expressed in baculovirus, also could prevent the aggregation of $A \beta$ in a model of cell-free $\mathrm{A} \beta$ aggregation (Zhang et al., 2015c). Besides, HT7 was obtained from the scFv antibody library of human, which was contributed by a healthy donor (Zhang Y. et al., 2019). HT7 antibody could disaggregate the A $\beta 42$ aggregates in vitro and inhibit cytotoxicity caused by $\mathrm{A} \beta 42$ in SH-SY5Y cells. The mechanism of A $\beta 42$ oligomeric subunits for effective anti-A $\beta 42$ antibodies called "post-saturation dissociation" was raised (Zhang Y. et al., 2019).

\section{Experiments of scFvs Targeting the $N$-Terminal Region of $A \beta$ In Vivo}

Gimenez-Llort et al. (2013) studied the protective effects of scFvh3D6 in the 3xTg-AD mice. They found that scFv-h3D6 could be effective in many aspects of 3xTg-AD mice, such as the recovery of swimming speed, improvement of memory and enhancement of learning ability. Treatment with scFv-h3D6 reduced the level of $\mathrm{A} \beta$ oligomers and apolipoproteins, including apoE and apoJ (Gimenez-Llort et al., 2013). Besides, Esquerda-Canals et al. (2013) also studied functions of scFv-h3D6 in the 3xTg-AD mice. They focused on deep cerebellar nuclei (DCN) neurons. In the early phase of $\mathrm{AD}$, some of these neurons could be dead. The scFv-h3D6 fragment could protect neurons from death, but not all of them, because of the insufficient dose in this study (Esquerda-Canals et al., 2013). Afterward, Esquerda-Canals et al. 
(2019b) observed that levels of intracellular A $\beta$ were decreased in the 3xTg-AD mice after injecting scFv-h3D6. It could prevent neurons from death. They also found that cognitive function was improved in terms of spatial memory according to the Morris Water Maze (MWM) tests (Esquerda-Canals et al., 2019b). Moreover, the treatment did not cause neuroinflammation. It was not harmful to the functions of kidney and liver, either. However, there were influences on spleen shown during the treatment, which indicated that spleen might be related to clearance of the combination of $\mathrm{A} \beta$ and scFv-h3D6 (EsquerdaCanals et al., 2019b). Roda et al. (2020a) proved the effect of scFvh3D6 on decreasing level of $\mathrm{A} \beta$ and improving impairment of cognition in the 3xTg-AD mice (Roda et al., 2020a). They suggested that applying scFv-h3D6 and stimulation of cognition together might be a strategy for treating AD (Roda et al., 2020a). Moreover, they found that levels of $A \beta$ and tau in the $3 \times T$ T-AD mice were both decreased after applying it. They also showed that scFv-h3D6 did not induce the response of inflammation (Roda et al., 2020b). Furthermore, another study also described the therapeutic effects of scFv-h3D6 in the 3xTgAD mice. The volume of brain was increased while levels of IL-6 and $\mathrm{A} \beta$ were decreased after applying scFv-h3D6 (Guell-Bosch et al., 2020). In terms of producing scFv-h3D6, it was proved that scFv-h3D6 could decrease the level of $\mathrm{A} \beta$ in the 3xTg-AD mice whether it was obtained from Escherichia coli or from Pichia pastoris (Montoliu-Gaya et al., 2017a). And scFv9 could protect effectively against memory deficit of drosophila caused by A $\beta 42$ deposits (Martin-Pena et al., 2017).

\section{ScFvs Targeting the Central Region of $A \beta$ (Amino Acids 17-32)}

Experiments of scFvs Targeting the Central Region of $A \beta$ In Vitro

B4. 4 could combine with the central part of $A \beta_{1-42}$ and inhibit the toxicity of fibrillar $A \beta_{1-42}$ and oligomeric $A \beta_{1-42}$ in SH-SY5Y cells (Solorzano-Vargas et al., 2008). Some scFvs have effects on inhibiting aggregation of $\mathrm{A} \beta$. Liu et al. (2004) discovered that H1v2 could combine with the 17-28 region of $A \beta$ and have effects on inhibiting the aggregation of $A \beta$. It could also eliminate the toxic effects caused by aggregation of A $\beta$ in SH-SY5Y cells (Liu et al., 2004). Besides, 1E8 scFv was obtained successfully and could combine with the central part of $A \beta$ (Nisbet et al., 2013). It was proven that $1 \mathrm{E} 8 \mathrm{scFv}$ could decrease fibril formation of $\mathrm{A} \beta_{1-42}$. The toxicity caused by $A \beta_{1-42}$ could be inhibited by $1 \mathrm{E} 8 \mathrm{scFv}$ in murine primary neuronal cultures and the P12 cell line (Nisbet et al., 2013). Besides, scFv 4.8 and scFv 3.20 prevented toxicity caused by oligomeric $A \beta_{1-42}$ in neuroblastoma cell cultures (Medecigo et al., 2010). The 25-35 fragment of $A \beta$ promotes $A \beta$ aggregation and causes toxicity. The study showed that scFvs called B6 and D4 against 25-35 fragment of $A \beta$ could restrain the aggregation of $A \beta 42$ and decrease the toxicity caused by A $\beta 42$ in SH-SY5Y cells (Zameer et al., 2006).

\section{Experiments of scFvs Targeting the Central Region of $A \beta$ In Vivo}

There were five fragments chosen and studied by Medecigo et al. (2010). ScFv 4.8 and scFv 3.20 could target central region of $\mathrm{A} \beta$.
After the intracranial injection, it was observed that $s c F v 4.8$ and scFv 3.20 identified amyloid deposits and decreased amyloid deposits specifically in the brains of APP/Tg2576 mice (Medecigo et al., 2010).

\section{ScFvs Targeting the C-Terminal Region of $A \beta$ (Amino Acids 33-42)}

ScFv42.2 targeted the C-terminal region of $\mathrm{A} \beta$. It could protect against memory deficit of drosophila (Martin-Pena et al., 2017). Drosophila model of $\mathrm{AD}$ can be used in studying the neuroprotective effect of novel scFvs. It was shown that scFv42.2 could inhibit the loss of neurons and improve neuron function. The effect of applying scFv9 and scFv42.2 together was also studied in drosophila (Fernandez-Funez et al., 2015). It was proven that their protective functions were synergistic, which indicated that applying scFvs targeting different epitopes together might be a more effective way to treat AD (Fernandez-Funez et al., 2015). ScFv17 targeting A 331 35 was obtained through genetic engineering technology of phage display (Hu et al., 2018). It was proven that scFv17 could penetrate $\mathrm{BBB}$ easily and had evident effects on decreasing the levels of $\mathrm{A} \beta$ oligomers and $\mathrm{A} \beta$ plaques in $\mathrm{APP} / \mathrm{PS} 1$ transgenic mice (Hu et al., 2018).

\section{ScFvs Targeting a Conformational Epitope (Monomers, Oligomers, Protofibrils and Fibrils)}

More and more evidences have shown that $A \beta$ oligomers, instead of fibrils or monomers, is the main toxic form inhibiting synaptic plasticity (Wang X.-p. et al., 2009). According to the study, four scFv antibodies including W8, W9, W20 and WC2, were obtained from human $\mathrm{scFv}$ library through phage display, which identified $A \beta$ oligomers specifically (Wang X.-p. et al., 2009). All of these scFv antibodies could combine with $\mathrm{A} \beta$ oligomers and prevent against the cytotoxicity in SH-SY5Y cells and fibrillation of A $\beta$ (Wang X.p. et al., 2009). A4 scFv antibody targeting $A \beta$ oligomers was proven to restrain $A \beta$ aggregation and decrease the toxicity in $\mathrm{SH}$ SY5Y cells (Zameer et al., 2008). Besides, A4 scFv was able to combine with $\mathrm{A} \beta$ aggregates in brain tissues of $\mathrm{AD}$ patients (Zameer et al., 2008). C6 scFv can also combine with oligomeric $\mathrm{A} \beta$ in 7PA2 cells and brain tissues of triple transgenic mice (Kasturirangan et al., 2013). It could be helpful in diagnosing neurodegenerative diseases and evaluating the treatment and development of disease (Kasturirangan et al., 2013). Similar with C6, NUscl is a scFv which targets A $\beta$ oligomers (Sebollela et al., 2017). It is potential to be used in the diagnosis and treatment in AD (Sebollela et al., 2017). It was reported that $\mathrm{scFv}$ MO6 could identify and combine with the oligomeric A $\beta 42$ selectively (Zhang et al., 2015a). It could decrease levels of oligomeric $A \beta 42$ by preventing their formation and disaggregate $\mathrm{A} \beta 42$ aggregation. $\mathrm{ScFv} \mathrm{MO} 6$ could also reduce the cytotoxicity caused by $\mathrm{A} \beta 42$ and improve viability of cell. And scFv MO6 could cross the BBB model in vitro (Zhang et al., 2015a). Moreover, scFv AS was identified and could combine with immature protofibrils as well as medium-size $A \beta$ oligomers (Zhang et al., 2015b). ScFv AS could decrease levels of A $\beta$ oligomers through preventing their formation or leading to their disaggregation (Zhang et al., 2015b). In this way, A $\beta$ 
cytotoxicity was inhibited. ScFv AS could also transport across the BBB model in vitro (Zhang et al., 2015b). What is more, scFv HT6 was able to combine with medium-sized $A \beta 42$ aggregation and lead to disaggregation of large $A \beta 42$ aggregation into small $A \beta 42$ oligomers (Zhang X. et al., 2019). At the same time, it could inhibit the progress of A $\beta 42$ aggregation. The effect of scFv HT6 on decreasing the cytotoxicity caused by $\mathrm{A} \beta 42$ oligomers was evident (Zhang X. et al., 2019). HT7 could target oligomers, protofibrils and fibrils (Zhang Y. et al., 2019). Besides, scFv-IC16 could recognize monomers, oligomers and fibrils (Dornieden et al., 2013). Besides, there are many scFvs targeting several conformational epitopes. Both $12 \mathrm{~B} 4-\mathrm{scFv}$ and $10 \mathrm{D} 5-\mathrm{scFv}$ could combine with $A \beta$ fibers, monomers and oligomers, as well as $A \beta$ plaque successfully. Moreover, the study showed that $10 \mathrm{D} 5-\mathrm{scFv}$ could combine with $\mathrm{A} \beta$ fibers and oligomers better than $12 \mathrm{~B} 4-\mathrm{scFv}$ (Fu et al., 2020).

\section{Adeno-Associated Virus as Vectors of scFvs}

Adeno-associated virus (AAV) can be vectors of scFvs (Levites et al., 2006). Levites et al. (2006) found that $A \beta$ deposition was reduced after injecting AAV1 containing the scFv (scFv9, scFv40.1 and scFv42.2) into the ventricles of CRND8-transgenic mice. Another study about injecting AAV containing the scFv59 into the corticohippocampal parts showed that the amyloid deposits were decreased compared with that of mice injected with PBS (Fukuchi et al., 2006). The existence of scFv59 could be detected easily in the neurons in a year after injecting AAV containing the scFv59 (Fukuchi et al., 2006). However, immunotherapy through recombinant AAV (rAAV) can cause hemorrhage by injecting it into ventricle (Kou et al., 2011). Researchers should pay attention to this point (Kou et al., 2011). Delivering scFv59 directed by muscle through rAAV1 was proven to be an efficient way of reducing $A \beta$ deposits in the brain (Yang et al., 2013). Reduced levels of $A \beta$ were observed in cerebrospinal fluid (CSF). However, incremental levels of $A \beta$ were shown in the serum (Yang et al., 2013). Wang Y.-J. et al. (2009) proved that delivering the scFv gene through AAV in an intramuscular way or in an intracranial way did not cause the increase of microhemorrhage, activation of microglia or evocation of $\mathrm{T}$ cells. Besides, the effect was similar in these two ways. The level of $A \beta$ was increased in serum while was decreased in the brain (Wang Y.-J. et al., 2009). The effect of delivering $s c F v$ gene intramuscularly was significant on inhibiting the formation of $A \beta$ plaque and preventing the accumulation of $\mathrm{A} \beta$. Besides, the cognitive impairment was also ameliorated through delivering $\mathrm{scFv}$ gene intramuscularly. Wang et al. (2010) proved that delivering $\mathrm{scFv}$ gene intramuscularly did not induce microhemorrhage or inflammation in the brain of $\mathrm{APP}_{\text {Swe }} /$ PS1dE9 transgenic mice (Wang et al., 2010). After intrahippocampally injecting $\mathrm{rAAV} 1$, insoluble $\mathrm{A} \beta$ was decreased and Morris Water Maze (MWM) showed that the cognition of mice was improved (Ryan et al., 2010).

\section{The Application of Fab Fragments in AD Experiments of the Application of Fab Fragments in AD In Vitro}

It was proven that $1 \mathrm{E} 8-4 \mathrm{~b}$ Fab could identify $\mathrm{A} \beta[1-40 / 42 / 43]$ peptides (Tammer et al., 2002). 1E8-4b Fab was able to combine with plaques in the brain tissue sections from CERAD-defined AD patients by immunohistochemistry (Tammer et al., 2002). It was demonstrated that $\mathrm{rFab}$ of $\mathrm{WO}-2$ had the ability of restraining the neurotoxicity caused by $\mathrm{A} \beta_{1-42}$ oligomer and depolymerizing the $A \beta_{1-42}$ fibrils formed previously (Robert et al., 2009). It was shown that humanized WO-2 Fab had the ability of inhibiting the toxicity caused by $\mathrm{A} \beta$ oligomer and aggregation (Robert et al., 2010). It could boost the disaggregation of amyloid fibrils (Robert et al., 2010). Fab can be combined with a quenchbody (Q-body), which is an antibodybased biosensor. This combination can be used in detection and imaging of $\mathrm{A} \beta$ aggregation, which may help diagnose $\mathrm{AD}$ (Dong et al., 2018).

\section{Experiments of the Application of Fab Fragments in AD In Vivo}

4396C is a mAb targeting GM1 ganglioside-bound $A \beta$ (GA $\beta$ ) specifically (Yamamoto et al., 2005). According to a study, Fab fragments of $4396 \mathrm{C}$ were effective in the inhibition of $\mathrm{A} \beta$ deposition in transgenic mice after the intraperitoneal injection of Fab fragments (Yamamoto et al., 2005). F(ab)'2 fragment belongs to an IgG1 mAb. The F(ab)'2 fragment was able to decrease $A \beta$ plaque formation in Tg2576 mice after the injection of it, whether in an intracranial way or in an intraperitoneal way (Tamura et al., 2005). Application of the $\mathrm{F}(\mathrm{ab})^{\prime} 2$ fragment decreased the infiltration of phagocytes compared with the complete mAb (Tamura et al., 2005). The Fab fragment which belonged to NT4X had the therapeutic effect on loss of neurons and memory impairment (Antonios et al., 2015).

\section{The Application of Single-Domain Antibody Fragments in AD}

Experiments of the Application of Single-Domain Antibody Fragments in AD In Vitro

The $\mathrm{VHH}$ is a single-chain domain binding to the antigen, which lacks light chain. The recombinant $\mathrm{VHH}$ has an intact antigenbinding domain with minimal size (Lafaye et al., 2009). VHHs acquired from an immunized alpaca phage display library, could identify $\mathrm{A} \beta$ oligomers with low molecular-weight (MW) selectively in neurons (Lafaye et al., 2009). VHH V31-1 was able to inhibit the formation of fibril and prevent the neurotoxicity caused by A $\beta$ (Lafaye et al., 2009). The study suggested that $\mathrm{VHH}$ V31-1 was potential in imaging and diagnosing AD (Lafaye et al., 2009). Hydrophobic complementarity-determining regions (CDRs) are able to boost the aggregation of antibody (Perchiacca et al., 2012). It was observed that the solubility of $\mathrm{VHH}$ could be increased by changing the sequence of CDR loops within them. In this way, the aggregation of antibodies would be resisted while their binding affinity would not be decreased. $\mathrm{VHH}$ used in this study was specific for $A \beta$ peptide and their specificity did not change (Perchiacca et al., 2012). Gammabody is a VH antibody against $A \beta$, which could identify $A \beta$ aggregations specifically with high affinity and decrease $A \beta$ toxicity (Zhang et al., 2018). $\mathrm{VH}$ antibody fragments obtained from the mouse immune library could decrease the toxicity caused by oligomeric A $\beta 42$ (Medecigo 
A Chitosan polymeric core
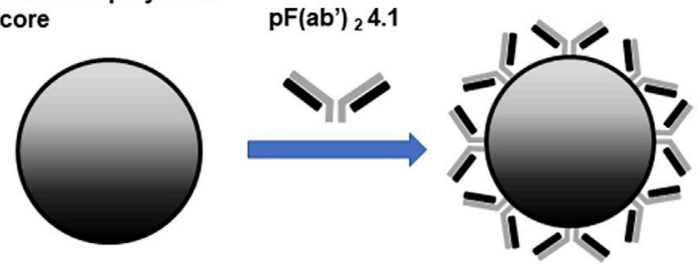

C

GSH-PEG liposome

VHH-pa2H
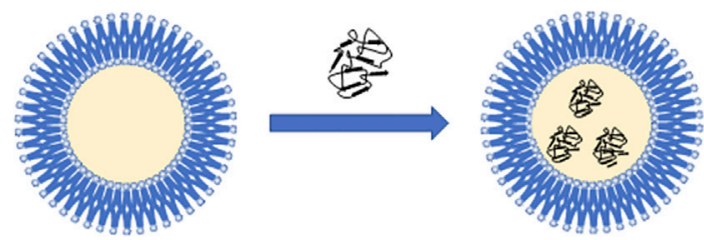

E

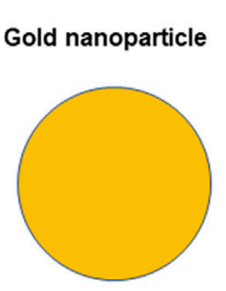

Half-antibody fragment of $O C$

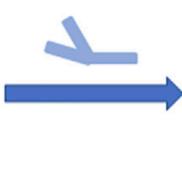

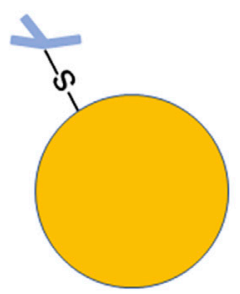

\section{B}

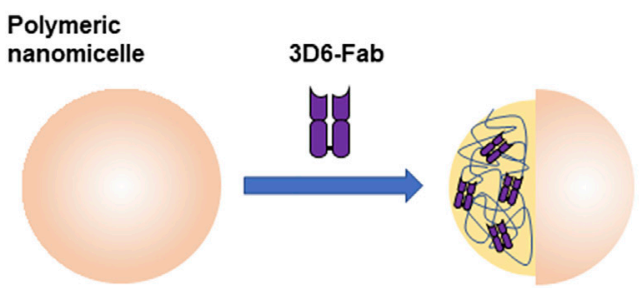

D Gold nanorod

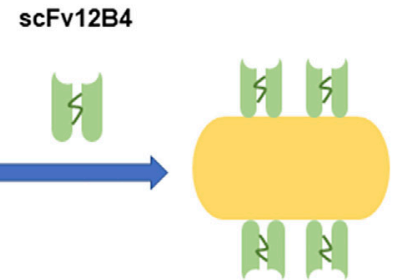

F Superparamagnetic iron oxide nanoparticle

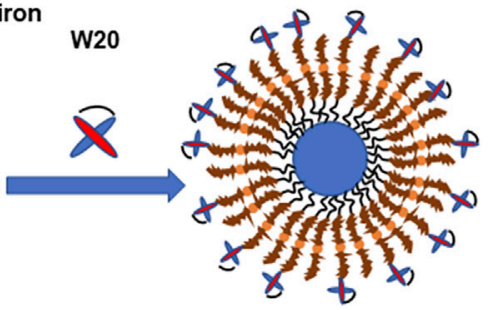

FIGURE 1 | The combined application of antibody fragments and nanoparticles in Alzheimer's disease. (A). PF(ab') ${ }_{2} 4.1$ cover the surface of the chitosan polymeric core. (B). Polymeric nanomicelle encapsulates 3D6-Fab. (C). GSH-PEG liposome encapsulates VHH-pa2H (D). ScFv $12 B 4$ are combined with gold nanorod (GNR). (E). Half-antibody fragment of OC is combined with gold nanoparticle (AuNP). (F). W2O is combined with superparamagnetic iron oxide nanoparticle (SPION). Different antibody fragments combine with different nanoparticles. Some antibody fragments are on the surface of the nanoparticle, while some are encapsulated in the nanoparticle. The combination of antibody fragments and nanoparticles can be used in the diagnosis or treatment of Alzheimer's disease.

et al., 2010). The specific combination of $\mathrm{VH}$ antibody fragments and $A \beta$ deposits was observed in the brain of Tg2576 mouse (Medecigo et al., 2010).

\section{Experiments of the Application of Single-Domain Antibody Fragments in AD In Vivo}

The size of llama VHH is small, which is about $12-15 \mathrm{kDa}$ (Rotman et al., 2015b). It could cross the BBB, but the BBB passage was poor (Rotman et al., 2015b). It was observed that VHHs could extravagate slowly to pass the BBB. It was shown that VHHs diffused in the parenchyma. Besides, the tangles of neurofibril and deposits of amyloid were labeled by VHHs ( $\mathrm{Li}$ et al., 2016). After delivering a $\mathrm{VH}$ fragment in an intracranial way, this fragment could decrease the amyloid burden in the Tg2576 mouse (Medecigo et al., 2010).

\section{THE COMBINED APPLICATION OF ANTIBODY FRAGMENTS AND NANOPARTICLES IN AD}

Nanoparticles can serve as drug delivery carriers to cross the BBB (Thangudu et al., 2020). Nanoparticles have many advantages. For example, nanoparticles can make hydrophobic drugs more stable and effective. And they can help drugs to target at tissues specifically and increase efficacy. Therefore, less doses can be effective and adverse effects will be decreased (Thangudu et al., 2020). Nanoparticles can pass through the BBB because their small sizes, often between 1 and $100 \mathrm{~nm}$ (Thangudu et al., 2020). Different kinds of nanoparticles have been used in the diagnosis and treatment of $\mathrm{AD}$, including polymeric nanoparticles, liposomes, magnetic nanoparticles and etc (Liu et al., 2019). Nowadays, the combination of nanoparticles and antibody fragments has been applied in the diagnosis and treatment of Alzheimer's disease. The following studies related to the combined application of antibody fragments and nanoparticles are summarized in Figure 1.

\section{The Combination of Fab Fragments and Polymeric Nanoparticles}

Polymeric nanoparticles are promising to be used in diagnosis and therapy of $\mathrm{AD}$ if they can pass through the $\mathrm{BBB}$ efficiently. Chitosan nanoparticles belong to polymeric nanoparticles (Agyare et al., 2008). There are several advantages of the chitosan nanoparticles (Agyare et al., 2008): 1) no allergic reactions induced; 2) effects on improving absorption of drugs; 
3) The producing condition is very mild, which guarantee the completeness of proteins and etc.; 4) the degradation product of chitosan in the body is nontoxic. However, it was still challenging for these nanoparticles to target amyloid deposits in the brain specifically (Agyare et al., 2008). In order to solve this problem, smart nano-vehicles (SNVs) were designed by Agyare et al. (2008). The polymeric core of SNV was made from chitosan nanoparticle. The $\mathrm{pF}\left(\mathrm{ab}^{\prime}\right)_{2}$ was used as the biosensor, which covered the surface of the nanoparticle core. $\mathrm{PF}\left(\mathrm{ab}^{\prime}\right)_{2}$ could detect deposits of amyloid specifically. $\mathrm{PF}\left(\mathrm{ab}^{\prime}\right)_{2}$ was obtained by using putrescine to modify a $\mathrm{F}(\mathrm{ab})_{2}$ fragment. It belongs to IgG4.1 against $\mathrm{A} \beta$. The $\mathrm{pF}\left(\mathrm{ab}^{\prime}\right)_{2}$ could cross $\mathrm{BBB}$ and combine with plaques and deposits of amyloid. Therefore, SNVs in this study were the chitosan polymeric cores (CPCs) covered with $\mathrm{PF}\left(\mathrm{ab}^{\prime}\right)_{2}$. Meanwhile, CPCs covered with a bovine serum albumin (BSA) were made as a control nano-vehicle (CNV). BSA applied in the control group was not specific and its molecular weight was similar to $\mathrm{pF}\left(\mathrm{ab}^{\prime}\right)_{2}$. The study showed that uptake of ${ }^{125}$ I-SNVs was much more than that of ${ }^{125} \mathrm{I}-\mathrm{CNV}$ s in the brain of mice. Therefore, they suggested that $\mathrm{pF}\left(\mathrm{ab}^{\prime}\right)_{2}$ enhanced the transcytosis of SNVs in the endothelial cells of BBB (Agyare et al., 2008). Afterward, Agyare et al. (2014) had another study about combining chitosan with $\mathrm{pF}\left(\mathrm{ab}^{\prime}\right)_{2}$. Different with the previous system, they added a MRI contrast agent and cyclophosphamide (CYC). This new system was called theranostic nanovehicles (TNVs). The MRI contrast agent Magnevist $^{\circledR}$ could detect the early stage of cerebral amyloid angiopathy (CAA). They loaded the core with CYC, which was able to inhibit cerebrovascular inflammation. They found that the productions of pro-inflammatory cytokine were decreased more effectively by using TVNs than using CYC alone. $\operatorname{PF}\left(\mathrm{ab}^{\prime}\right)_{2} 4.1$ that was on the surface of this nanocore could combine with amyloid. TVNs were able to target accumulation of amyloid in the brain of mice. Besides, they observed that TVNs could prevent production of cytokines caused by the exposure of A $\beta 40$ (Agyare et al., 2014). Another application of combining polymeric nanoparticles and antibody fragment is studied by Xie et al. (2020). The system of polymeric nanomicelle (PM) was provided to deliver 3D6-Fab. After applying the system of PM, they found that 3D6-Fab was transported more into the brain of $\mathrm{AD}$ mice than using this fragment alone. The accumulation of this fragment was 41 times in the system of PM than using 3D6-Fab without this system. It was observed the aggregation of $A \beta_{1-42}$ was restrained in the way of transporting 3D6-Fab through this system. 3D6-Fab absorbed by peripheral tissues was minimal. It was proven that the effect on treating AD was increased significantly by using 3D6-Fab combined with PM system compared with that of applying free 3D6-Fab (Xie et al., 2020).

\section{The Combination of VHH and Liposomes}

Liposomes are also used as carriers widely. Liposome contains an aqueous core and the lipid bilayer, whose unique structure is able to carry many different kinds of agents (Gopalan et al., 2020). Liposomes are nanometric and they can target certain domains specifically (Gopalan et al., 2020). VHH could be applied in the detection of $A \beta$ deposits based on their high affinity to $A \beta$ deposits. VHHs were also able to cross the model of $\mathrm{BBB}$ in vitro. VHHs were non-immunogenic and had been applied in clinical trials of human (Rotman et al., 2015a). According to the previous study, the renal clearance of $\mathrm{VHH}$ given in the intravenous way was rapid and the half-lives in blood were about 10-20 min, leading to the limited BBB passage. Therefore, GSH-PEG liposomes were developed in order to extend its time of staying in the blood, deliver $\mathrm{VHH}$ and make it pass through the BBB (Rotman et al., 2015a). This study offered a potential platform for diagnosing and treating $\mathrm{AD}$ by using VHH. VHH-pa2H was radiolabeled with indium-111 ( $\left.{ }^{111} \mathrm{In}\right)$ and DTPA so that VHH-pa2H itself could be traced (Rotman et al., 2015a). Two formulations of GSH-PEG liposomes which loaded VHH-pa2H-DTPA- ${ }^{111}$ In were designed in the delivery of $\mathrm{VHH}$. They found that liposomes were able to improve bioavailability and extend residence of $\mathrm{VHH}$ in the blood. In comparison with free $\mathrm{VHH}-\mathrm{pa} 2 \mathrm{H}$, standard uptake values (SUV) were increased in the both formulations of GSH-PEG liposomes. VHH were able to be delivered into the brains of transgenic mice by GSH-PEG liposomes (Rotman et al., 2015a).

\section{The Combination of Antibody Fragments and Gold Nanoparticles}

Gold nanoparticles (AuNPs) have excellent biocompatibility, stability and optical properties (Liu et al., 2019). Gold nanoparticles can be bioconjugated and functionalized easily. Their advantages make them become outstanding candidate in comparison with other nanoparticles. It was reported that combination of amyloid-degrading enzymes (ADEs), nanoparticles and scFvs had the capacity of reducing neurotoxicity by disaggregating $A \beta$ fibrils and restraining aggregation of A $\beta$. Liu et al. (2019) made a complex called GNRs-APH-scFv (GAS). It was consisted of scFv 12B4, thermophilic acylpeptide hydrolase (APH) ST0779 and gold nanorods (GNRs). GNRs could produce hyperthermia by converting optical energy. GNRs were more effective in absorbing energy of near infrared (NIR) light than spherical AuNPs (Liu et al., 2019). Local hyperthermia could dissolve $\mathrm{A} \beta$ aggregations. $\mathrm{ScFv}$ binding to $\mathrm{A} \beta$ oligomers and fibrils, made hyperthermia specific, which decreased damage to other normal tissues. ST0779 could hydrolyze A $\beta$ monomers. Multifunctional GAS complex could detect aggregation of $A \beta$ and clear excessive $A \beta$ by activating this entire system with NIR light after detecting $A \beta$. This complex can restrain aggregation of $A \beta$, disassemble fibrils of $A \beta$ and decrease activity of peroxidase caused by $A \beta$. The $A \beta$ cytotoxicity was decreased (Liu et al., 2019). Besides, there is another study about AuNPs and antibody fragments. An antibody against fibril of $A \beta_{1-42}$ is called OC. Immobilizing the half fragment of OC on AuNPs was able to make an immunosensor. Palla et al. (2021) proved that the immunosensor could detect fibril of $A \beta_{1-42}$ and evaluate the progress of AD (Palla et al., 2021).

\section{The Combination of Antibody Fragments and Superparamagnetic Iron Oxide Nanoparticles}

Superparamagnetic iron oxide nanoparticles (SPIONs) are usually used in imaging as MRI contrast agents (Thangudu 
et al., 2020). Liu X.-G. et al. (2020) made a system called W20/ XD4-SPIONs. They studied the effects of it on diagnosing and treating AD. SPIONs can transport through the BBB because of their small sizes. $A \beta$ oligomers ( $A \beta O$ s) have important effect on causing dementia. W20, which is a scFv, could identify oligomers of amyloid specifically (Liu X.-G. et al., 2020). Phagocytosis of $\mathrm{A} \beta \mathrm{O}$ s could be boosted by XD4. The class A scavenger receptor (SR-A) was activated by XD4. PEGylated SPIONs were combined with XD4 and W20. It was studied that W20/XD4-SPIONs boosted the phagocytosis of A $\beta$ obviously because of the effect of XD40 on SR-A. W20/XD4-SPIONs could pass through the BBB. They could arrive at region of oligomers in the brain of $\mathrm{AD}$ transgenic mice according to the MRI. Their combinations with A $\beta O$ s were sensitive and specific. They can be used in the diagnosis of AD in the early phase. Besides, W20/XD4-SPIONs could be used in treating $\mathrm{AD}$ because they can restrain the aggregation of $A \beta$. (Liu X.-G. et al., 2020). It was proved that W20/XD4-SPIONs could reduce cytotoxicity caused by $\mathrm{A} \beta \mathrm{O}$. As for microglia, phagocytosis of $\mathrm{A} \beta$ was improved. And the cognition impairments and neuropathology were ameliorated by W20/XD4-SPIONs in AD mice (Liu X.-g. et al., 2020).

Taken together, different nanoparticles can be combined with antibody fragments including scFv, Fab fragment and singledomain antibody fragment. Their combination could facilitate the penetration of $\mathrm{BBB}$ and provide multiple therapeutic effects. Among these complexes, we prefer the combined application of antibody fragments and gold nanoparticles, which integrated diagnosis and treatment in one system. And local hyperthermia could dissolve $A \beta$ aggregations. Furthermore, multifunctional GAS complex had less side effects due to its high specificity. Therefore, the combination of nanoparticles and antibody fragments may have more advantages in diagnosing and treating $\mathrm{AD}$.

\section{SUMMARY}

It is promising to apply antibody fragments against $A \beta$ in the diagnosis and treatment of AD. Antibody fragments have been further developed, because of their advantages over mAbs. Nanoparticles are potential candidates for drug delivery. A

\section{REFERENCES}

Agyare, E. K., Curran, G. L., Ramakrishnan, M., Yu, C. C., Poduslo, J. F., and Kandimalla, K. K. (2008). Development of a Smart Nano-Vehicle to Target Cerebrovascular Amyloid Deposits and Brain Parenchymal Plaques Observed in Alzheimer's Disease and Cerebral Amyloid Angiopathy. Pharm. Res. 25, 2674-2684. doi:10.1007/s11095-0089688-y

Agyare, E. K., Jaruszewski, K. M., Curran, G. L., Rosenberg, J. T., Grant, S. C., Lowe, V. J., et al. (2014). Engineering Theranostic Nanovehicles Capable of Targeting Cerebrovascular Amyloid Deposits. J. Controlled Release 185, 121-129. doi:10. 1016/j.jconrel.2014.04.010

Antonios, G., Borgers, H., Richard, B. C., Brauss, A., Meissner, J., Weggen, S., et al. (2015). Alzheimer Therapy with an Antibody against N-Terminal Abeta 4-X and Pyroglutamate Abeta 3-X. Sci. Rep. 5, 17338. doi:10.1038/srep17338 very important advantage of nanoparticles is that they can bind with many substances and deliver them to targeted regions. Nanoparticles can bind different agents with multiple functions to treat $\mathrm{AD}$, which may take synergistic effects. Besides, nanoparticles can be combined with detective agents and treatment agents at the same time, integrating diagnosis and treatment in one system. Therefore, the combination of antibody fragments and nanoparticles becomes a system. This system can preserve and even enhance the functions of antibody fragments. In addition, many aspects should be paid attention to and further studied, for example, improving the specificity and stability of the combination and evaluating the potential toxicity. In the future, more and more combined application of antibody fragments and nanoparticles will be developed. All in all, combining antibody fragments with nanoparticles is a promising strategy in the diagnosis and treatment of $\mathrm{AD}$.

\section{AUTHOR CONTRIBUTIONS}

Z-TS, CM, G-JL, and X-YZ searched the literature and drafted the manuscript. Y-TH made the figure. XW and YY critically revised the manuscript. All authors listed have made a substantial, direct and intellectual contribution to the work, and approved it for publication.

\section{FUNDING}

This study was supported by grants from the National Natural Science Foundation of China (No. 81901083), the Key National Research Projects on Prevention and Control of Major Chronic Non-communicable Disease (2018YFC1312300), as well as from Fund of Science and Technology Development Project of Jilin Province (20180414041GH) and Jilin Health Technology Innovation Project (2019J003).

\section{ACKNOWLEDGMENTS}

We would like to thank Editage for English language editing.

Behl, T., Kaur, I., Fratila, O., Brata, R., and Bungau, S. (2020). Exploring the Potential of Therapeutic Agents Targeted towards Mitigating the Events Associated with Amyloid- $\beta$ Cascade in Alzheimer's Disease. Ijms 21, 7443. doi:10.3390/ijms21207443

Bitencourt, A. L. B., Campos, R. M., Cline, E. N., Klein, W. L., and Sebollela, A. (2020). Antibody Fragments as Tools for Elucidating Structure-Toxicity Relationships and for Diagnostic/Therapeutic Targeting of Neurotoxic Amyloid Oligomers. Ijms 21, 8920. doi:10.3390/ijms21238920

Dong, J., Fujita, R., Zako, T., and Ueda, H. (2018). Construction of Quenchbodies to Detect and Image Amyloid $\beta$ Oligomers. Anal. Biochem. 550, 61-67. doi:10. 1016/j.ab.2018.04.016

Dornieden, S., Müller-Schiffmann, A., Sticht, H., Jiang, N., Cinar, Y., Wördehoff, M., et al. (2013). Characterization of a Single-Chain Variable Fragment Recognizing a Linear Epitope of A $\beta$ : A Biotechnical Tool for Studies on Alzheimer's Disease? PLoS One 8, e59820. doi:10.1371/ journal.pone.0059820 
Esquerda-Canals, G., Marti, J., Rivera-Hernández, G., Giménez-Llort, L., and Villegas, S. (2013). Loss of Deep Cerebellar Nuclei Neurons in the 3xTg-AD Mice and Protection by an Anti-amyloid $\beta$ Antibody Fragment. MAbs 5, 660-664. doi:10.4161/mabs.25428

Esquerda-Canals, G., Martí-Clúa, J., and Villegas, S. (2019a). Pharmacokinetic Parameters and Mechanism of Action of an Efficient Anti-a $\beta$ Single Chain Antibody Fragment. PLoS One 14, e0217793, doi:10.1371/journal.pone.0217793

Esquerda-Canals, G., Roda, A. R., Martí-Clúa, J., Montoliu-Gaya, L., RiveraHernández, G., and Villegas, S. (2019b). Treatment with scFv-h3D6 Prevented Neuronal Loss and Improved Spatial Memory in Young 3xTg$\mathrm{AD}$ Mice by Reducing the Intracellular Amyloid- $\beta$ Burden. Jad 70, 1069-1091. doi:10.3233/JAD-190484

Fernandez-Funez, P., Zhang, Y., Sanchez-Garcia, J., De Mena, L., Khare, S., Golde, T. E., et al. (2015). Anti-A $\beta$ Single-Chain Variable Fragment Antibodies Exert Synergistic Neuroprotective Activities inDrosophilamodels of Alzheimer's Disease. Hum. Mol. Genet. 24, 6093-6105. doi:10.1093/hmg/ddv321

Fu, L., Zhang, Y., Zhang, X., Tian, W., Zhang, W., Jia, Y., et al. (2020). Preparation and In Vitro Activity of Single Chain Antibodies against Alzheimer's Disease. Immunol. Lett. 227, 1-7. doi:10.1016/j.imlet.2020.07.009

Fukuchi, K.-i., Tahara, K., Kim, H.-D., Maxwell, J. A., Lewis, T. L., Accavitti-Loper, M. A., et al. (2006). Anti-A $\beta$ Single-Chain Antibody Delivery via AdenoAssociated Virus for Treatment of Alzheimer's Disease. Neurobiol. Dis. 23, 502-511. doi:10.1016/j.nbd.2006.04.012

Giménez-Llort, L., Rivera-Hernández, G., Marín-Argany, M., Sánchez-Quesada, J. L., and Villegas, S. (2013). Early Intervention in the 3xTg-AD Mice with an Amyloid $\beta$-antibody Fragment Ameliorates First Hallmarks of Alzheimer Disease. MAbs 5, 665-864. doi:10.4161/mabs.25424

Gopalan, D., Pandey, A., Alex, A. T., Kalthur, G., Pandey, S., Udupa, N., et al. (2021). Nanoconstructs as a Versatile Tool for Detection and Diagnosis of Alzheimer Biomarkers. Nanotechnology 32, 142002. doi:10.1088/1361-6528/abcdcb

Güell-Bosch, J., Lope-Piedrafita, S., Esquerda-Canals, G., Montoliu-Gaya, L., and Villegas, S. (2020). Progression of Alzheimer's Disease and Effect of scFv-h3D6 Immunotherapy in the 3xTg-AD Mouse Model: An In Vivo Longitudinal Study Using Magnetic Resonance Imaging and Spectroscopy. NMR Biomed. 33, e4263, doi: $10.1002 / \mathrm{nbm} .4263$

Holmes, C., and Amin, J. (2020). Dementia. Medicine 48, 742-745. doi:10.1016/j. mpmed.2020.08.014

Hu, M., Zhang, J., Yang, J., Cao, Y., and Qi, J. (2018). A Novel scFv Anti-aß Antibody Reduces Pathological Impairments in APP/PS1 Transgenic Mice via Modulation of Inflammatory Cytokines and A $\beta$-Related Enzymes. J. Mol. Neurosci. 66, 1-9. doi:10.1007/s12031-018-1139-6

Kasturirangan, S., Reasoner, T., Schulz, P., Boddapati, S., Emadi, S., Valla, J., et al. (2013). Isolation and Characterization of Antibody Fragments Selective for Specific Protein Morphologies from Nanogram Antigen Samples. Biotechnol. Prog. 29, 463-471. doi:10.1002/btpr.1698

Kou, J., Kim, H., Pattanayak, A., Song, M., Lim, J.-E., Taguchi, H., et al. (2011). Anti-Amyloid- $\beta$ Single-Chain Antibody Brain Delivery via AAV Reduces Amyloid Load but May Increase Cerebral Hemorrhages in an Alzheimer's Disease Mouse Model. Jad 27, 23-38. doi:10.3233/JAD-2011-110230

Lafaye, P., Achour, I., England, P., Duyckaerts, C., and Rougeon, F. (2009). Singledomain Antibodies Recognize Selectively Small Oligomeric Forms of Amyloid $\beta$, Prevent $A \beta$-Induced Neurotoxicity and Inhibit Fibril Formation. Mol. Immunol. 46, 695-704. doi:10.1016/j.molimm.2008.09.008

Levites, Y., Jansen, K., Smithson, L. A., Dakin, R., Holloway, V. M., Das, P., et al. (2006). Intracranial Adeno-Associated Virus-Mediated Delivery of Anti-pan Amyloid Beta, Amyloid Beta40, and Amyloid Beta42 Single-Chain Variable Fragments Attenuates Plaque Pathology in Amyloid Precursor Protein Mice. J. Neurosci. 26, 11923-11928. doi:10.1523/JNEUROSCI.2795-06.2006

Li, T., Vandesquille, M., Koukouli, F., Dudeffant, C., Youssef, I., Lenormand, P., et al. (2016). Camelid Single-Domain Antibodies: A Versatile Tool for In Vivo Imaging of Extracellular and Intracellular Brain Targets. J. Controlled Release 243, 1-10. doi:10.1016/j.jconrel.2016.09.019

Liu, D., Li, W., Jiang, X., Bai, S., Liu, J., Liu, X., et al. (2019). Using Near-Infrared Enhanced Thermozyme and scFv Dual-Conjugated Au Nanorods for Detection and Targeted Photothermal Treatment of Alzheimer's Disease. Theranostics 9, 2268-2281. doi:10.7150/thno.30649

Liu, R., Yuan, B., Emadi, S., Zameer, A., Schulz, P., Mcallister, C., et al. (2004). Single Chain Variable Fragments against $\beta$-Amyloid $(A \beta)$ Can Inhibit $A \beta$
Aggregation and Prevent A $\beta$-Induced Neurotoxicity†. Biochemistry 43, 6959-6967. doi:10.1021/bi049933o

Liu, X.-g., Zhang, L., Lu, S., Liu, D.-q., Huang, Y.-r., Zhu, J., et al. (2020). Superparamagnetic Iron Oxide Nanoparticles Conjugated with $A \beta$ Oligomer-specific scFv Antibody and Class A Scavenger Receptor Activator Show Therapeutic Potentials for Alzheimer's Disease. J. Nanobiotechnol 18, 160. doi:10.1186/s12951-020-00723-1

Liu, X.-G., Zhang, L., Lu, S., Liu, D.-Q., Zhang, L.-X., Yu, X.-L., et al. (2020). Multifunctional Superparamagnetic Iron Oxide Nanoparticles Conjugated with A $\beta$ Oligomer-specific scFv Antibody and Class A Scavenger Receptor Activator Show Early Diagnostic Potentials for Alzheimer's Disease. Ijn 15, 4919-4932. doi:10.2147/IJN.S240953

Marín-Argany, M., Rivera-Hernández, G., Martí, J., and Villegas, S. (2011). An Anti-a $\beta$ (Amyloid $\beta$ ) Single-Chain Variable Fragment Prevents Amyloid Fibril Formation and Cytotoxicity by Withdrawing $A \beta$ Oligomers from the Amyloid Pathway. Biochem. J. 437, 25-34. doi:10.1042/BJ20101712

Martin-Peña, A., Rincon-Limas, D. E., and Fernandez-Funez, P. (2017). Anti-A $\beta$ Single-Chain Variable Fragment Antibodies Restore Memory Acquisition in a Drosophila Model of Alzheimer's Disease. Sci. Rep. 7, 11268. doi:10.1038/ s41598-017-11594-2

Medecigo, M., Manoutcharian, K., Vasilevko, V., Govezensky, T., Munguia, M. E., Becerril, B., et al. (2010). Novel Amyloid-Beta Specific scFv and VH Antibody Fragments from Human and Mouse Phage Display Antibody Libraries. J. Neuroimmunology 223, 104-114. doi:10.1016/j.jneuroim.2010.03.023

Montoliu-Gaya, L., Esquerda-Canals, G., Bronsoms, S., and Villegas, S. (2017a). Production of an Anti-a $\beta$ Antibody Fragment in Pichia pastoris and In Vitro and In Vivo Validation of its Therapeutic Effect. PLoS One 12, e0181480. doi:10. 1371/journal.pone. 0181480

Montoliu-Gaya, L., Martínez, J. C., and Villegas, S. (2017b). Understanding the Contribution of Disulfide Bridges to the Folding and Misfolding of an Anti-a $\beta$ scFv. Protein Sci. 26, 1138-1149. doi:10.1002/pro.3164

Nisbet, R. M., Nigro, J., Breheney, K., Caine, J., Hattarki, M. K., and Nuttall, S. D. (2013). Central Amyloid- -specific Single Chain Variable Fragment Ameliorates A Aggregation and Neurotoxicity. Protein Eng. Des. Selection 26, 571-580. doi:10.1093/protein/gzt025

Palla, G., Malecka, K., Dehaen, W., Radecki, J., and Radecka, H. (2021). Immunosensor Incorporating Half-Antibody Fragment for Electrochemical Monitoring of Amyloid- $\beta$ Fibrils in Artificial Blood Plasma. Bioelectrochemistry 137, 107643. doi:10.1016/j.bioelechem.2020.107643

Perchiacca, J. M., Ladiwala, A. R. A., Bhattacharya, M., and Tessier, P. M. (2012). Aggregation-resistant Domain Antibodies Engineered with Charged Mutations Near the Edges of the Complementarity-Determining Regions. Protein Eng. Des. Selection 25, 591-602. doi:10.1093/protein/gzs042

Robert, R., Dolezal, O., Waddington, L., Hattarki, M. K., Cappai, R., Masters, C. L., et al. (2009). Engineered Antibody Intervention Strategies for Alzheimer's Disease and Related Dementias by Targeting Amyloid and Toxic Oligomers. Protein Eng. Des. Selection 22, 199-208. doi:10.1093/ protein/gzn052

Robert, R., Streltsov, V. A., Newman, J., Pearce, L. A., Wark, K. L., and Dolezal, O. (2010). Germline Humanization of a Murine A $\beta$ Antibody and Crystal Structure of the Humanized Recombinant Fab Fragment. Protein Sci. 19, 299-308. doi:10.1002/pro.312

Robert, R., and Wark, K. L. (2012). Engineered Antibody Approaches for Alzheimer's Disease Immunotherapy. Arch. Biochem. Biophys. 526, 132-138. doi:10.1016/j.abb.2012.02.022

Roda, A. R., Esquerda-Canals, G., Martí-Clúa, J., and Villegas, S. (2020a). Cognitive Impairment in the 3xTg-AD Mouse Model of Alzheimer's Disease Is Affected by A $\beta$-ImmunoTherapy and Cognitive Stimulation. Pharmaceutics 12, 944. doi:10.3390/pharmaceutics12100944

Roda, A. R., Montoliu-Gaya, L., Serra-Mir, G., and Villegas, S. (2020b). Both Amyloid- $\beta$ Peptide and Tau Protein Are Affected by an Anti-amyloid- $\beta$ Antibody Fragment in Elderly 3xTg-AD Mice. Ijms 21, 6630. doi:10.3390/ ijms 21186630

Rotman, M., Welling, M. M., Bunschoten, A., De Backer, M. E., Rip, J., Nabuurs, R. J. A., et al. (2015a). Enhanced Glutathione PEGylated Liposomal Brain Delivery of an Anti-amyloid Single Domain Antibody Fragment in a Mouse Model for Alzheimer's Disease. J. Controlled Release 203, 40-50. doi:10.1016/j.jconrel. 2015.02.012 
Rotman, M., Welling, M. M., Van Den Boogaard, M. L., Moursel, L. G., Van Der Graaf, L. M., Van Buchem, M. A., et al. (2015b). Fusion of hIgG1-Fc to 111InAnti-Amyloid Single Domain Antibody Fragment VHH-pa2H Prolongs Blood Residential Time in APP/PS1 Mice but Does Not Increase Brain Uptake. Nucl. Med. Biol. 42, 695-702. doi:10.1016/j.nucmedbio.2015.03.003

Ryan, D. A., Mastrangelo, M. A., Narrow, W. C., Sullivan, M. A., Federoff, H. J., and Bowers, W. J. (2010). A $\beta$-directed Single-Chain Antibody Delivery via a Serotype-1 AAV Vector Improves Learning Behavior and Pathology in Alzheimer's Disease Mice. Mol. Ther. 18, 1471-1481. doi:10.1038/mt.2010.111

Sebollela, A., Cline, E. N., Popova, I., Luo, K., Sun, X., Ahn, J., et al. (2017). A Human scFv Antibody that Targets and Neutralizes High Molecular Weight Pathogenic Amyloid- $\beta$ Oligomers. J. Neurochem. 142, 934-947. doi:10.1111/ jnc. 14118

Solórzano-Vargas, R. S., Vasilevko, V., Acero, G., Ugen, K. E., Martinez, R., Govezensky, T., et al. (2008). Epitope Mapping and Neuroprotective Properties of a Human Single Chain FV Antibody that Binds an Internal Epitope of Amyloid-Beta 1-42. Mol. Immunol. 45, 881-886. doi:10.1016/j. molimm.2007.08.008

Tammer, A. H., Coia, G., Cappai, R., Fuller, S., Masters, C. L., Hudson, P., et al. (2002). Generation of a Recombinant Fab Antibody Reactive with the Alzheimer's Disease-Related A $\beta$ Peptide. Clin. Exp. Immunol. 129, 453-463. doi:10.1046/j.1365-2249.2002.01905.x

Tamura, Y., Hamajima, K., Matsui, K., Yanoma, S., Narita, M., Tajima, N., et al. (2005). The $\mathrm{F}\left(\mathrm{ab}^{\prime}\right) 2$ Fragment of an $\mathrm{A} \beta$-specific Monoclonal Antibody Reduces A $\beta$ Deposits in the Brain. Neurobiol. Dis. 20, 541-549. doi:10.1016/j.nbd.2005. 04.007

Thangudu, S., Cheng, F.-Y., and Su, C.-H. (2020). Advancements in the BloodBrain Barrier Penetrating Nanoplatforms for Brain Related Disease Diagnostics and Therapeutic Applications. Polymers 12, 3055. doi:10.3390/polym12123055

Tian Hui Kwan, A., Arfaie, S., Therriault, J., Rosa-Neto, P., and Gauthier, S. (2020). Lessons Learnt from the Second Generation of Anti-amyloid Monoclonal Antibodies Clinical Trials. Dement Geriatr. Cogn. Disord. 49, 334-348. doi:10.1159/000511506

Uddin, M. S., Kabir, M. T., Rahman, M. S., Behl, T., Jeandet, P., Ashraf, G. M., et al. (2020). Revisiting the Amyloid Cascade Hypothesis: From Anti-a $\beta$ Therapeutics to Auspicious New Ways for Alzheimer's Disease. Ijms 21, 5858. doi:10.3390/ijms 21165858

Wang, X.-p., Zhang, J.-h., Wang, Y.-j., Feng, Y., Zhang, X., Sun, X.-x., et al. (2009). Conformation-dependent Single-chain Variable Fragment Antibodies Specifically Recognize Beta-amyloid Oligomers. FEBS Lett. 583, 579-584. doi:10.1016/j.febslet.2008.12.064

Wang, Y.-J., Gao, C.-Y., Yang, M., Liu, X.-H., Sun, Y., Pollard, A., et al. (2010). Intramuscular Delivery of a Single Chain Antibody Gene Prevents Brain A $\beta$ Deposition and Cognitive Impairment in a Mouse Model of Alzheimer's Disease. Brain Behav. Immun. 24, 1281-1293. doi:10.1016/j.bbi.2010.05.010

Wang, Y.-J., Pollard, A., Zhong, J.-H., Dong, X.-Y., Wu, X.-B., Zhou, H.-D., et al. (2009). Intramuscular Delivery of a Single Chain Antibody Gene Reduces Brain A $\beta$ Burden in a Mouse Model of Alzheimer's Disease. Neurobiol. Aging 30, 364-376. doi:10.1016/j.neurobiolaging.2007.06.013

Xie, J., Gonzalez-Carter, D., Tockary, T. A., Nakamura, N., Xue, Y., Nakakido, M., et al. (2020). Dual-Sensitive Nanomicelles Enhancing Systemic Delivery of
Therapeutically Active Antibodies Specifically into the Brain. ACS Nano 14, 6729-6742. doi:10.1021/acsnano.9b09991

Yamamoto, N., Yokoseki, T., Shibata, M., Yamaguchi, H., and Yanagisawa, K. (2005). Suppression of $A \beta$ Deposition in Brain by Peripheral Administration of Fab Fragments of Anti-seed Antibody. Biochem. Biophysical Res. Commun. 335, 45-47. doi:10.1016/j.bbrc.2005.06.208

Yang, J., Pattanayak, A., Song, M., Kou, J., Taguchi, H., Paul, S., et al. (2013). Muscle-Directed Anti-a $\beta$ Single-Chain Antibody Delivery via AAV1 Reduces Cerebral A $\beta$ Load in an Alzheimer's Disease Mouse Model. J. Mol. Neurosci. 49, 277-288. doi:10.1007/s12031-012-9877-3

Zameer, A., Kasturirangan, S., Emadi, S., Nimmagadda, S. V., and Sierks, M. R. (2008). Anti-oligomeric A $\beta$ Single-Chain Variable Domain Antibody Blocks A $\beta$-Induced Toxicity against Human Neuroblastoma Cells. J. Mol. Biol. 384, 917-928. doi:10.1016/j.jmb.2008.09.068

Zameer, A., Schulz, P., Wang, M. S., and Sierks, M. R. (2006). Single Chain Fv Antibodies against the 25-35 A $\beta$ Fragment Inhibit Aggregation and Toxicity of A $\beta 42 \uparrow$. Biochemistry 45, 11532-11539. doi:10.1021/bi060601o

Zhang, M., Zheng, J., Nussinov, R., and Ma, B. (2018). Molecular Recognition between A $\beta$-specific Single-Domain Antibody and A $\beta$ Misfolded Aggregates. Antibodies 7, 25. doi:10.3390/antib7030025

Zhang, X., Huai, Y., Cai, J., Song, C., and Zhang, Y. (2019). Novel Antibody against Oligomeric Amyloid- $\beta$ : Insight into Factors for Effectively Reducing the Aggregation and Cytotoxicity of Amyloid- $\beta$ Aggregates. Int. Immunopharmacology 67, 176-185. doi:10.1016/j.intimp.2018.12.014

Zhang, Y., Chen, X., Liu, J., and Zhang, Y. (2015a). The Protective Effects and Underlying Mechanism of an Anti-oligomeric A $\beta 42$ Single-Chain Variable Fragment Antibody. Neuropharmacology 99, 387-395. doi:10.1016/j. neuropharm.2015.07.038

Zhang, Y., Huai, Y., Zhang, X., Song, C., Cai, J., and Zhang, Y. (2019). The Mode of Action of an Anti-oligomeric Amyloid $\beta$-Protein Antibody Affects its Protective Efficacy. Neurotox Res. 35, 304-317. doi:10.1007/s12640-018-9955-6

Zhang, Y., Sun, Y., Huai, Y., and Zhang, Y.-J. (2015b). Functional Characteristics and Molecular Mechanism of a New scFv Antibody against A $\beta 42$ Oligomers and Immature Protofibrils. Mol. Neurobiol. 52, 1269-1281. doi:10.1007/s12035-0148910-7

Zhang, Y., Yang, H.-Q., Fang, F., Song, L.-L., Jiao, Y.-Y., Wang, H., et al. (2015c). Single Chain Variable Fragment against A $\beta$ Expressed in Baculovirus Inhibits Abeta Fibril Elongation and Promotes its Disaggregation. PLoS One 10, e0124736, doi:10.1371/journal.pone.0124736

Conflict of Interest: The authors declare that the research was conducted in the absence of any commercial or financial relationships that could be construed as a potential conflict of interest.

Copyright (c) 2021 Sun, Ma, Li, Zheng, Hao, Yang and Wang. This is an open-access article distributed under the terms of the Creative Commons Attribution License (CC $B Y)$. The use, distribution or reproduction in other forums is permitted, provided the original author(s) and the copyright owner(s) are credited and that the original publication in this journal is cited, in accordance with accepted academic practice. No use, distribution or reproduction is permitted which does not comply with these terms. 


\section{GLOSSARY}

AD: Alzheimer's disease

A $\beta$ : amyloid- $\beta$

AAV: adeno-associated virus

A $\beta$ O: $A \beta$ oligomer

ADE: amyloid-degrading enzyme

APH: acylpeptide hydrolase

BBB: blood-brain barrier

BSA: bovine serum albumin

CDR: complementarity-determining region

CSF: cerebrospinal fluid

CPC: chitosan polymeric core

CNV: control nano-vehicle

CYC: cyclophosphamide

CAA: cerebral amyloid angiopathy

DCN: deep cerebellar nuclei

Fc: crystallizable fraction
GAS: GNRs-APH-scFv

GNR: gold nanorod

GA $\beta$ : ganglioside-bound $\mathrm{A} \beta$

MWM: Morris Water Maze

MP: mimetic peptide

MW: molecular-weight

mAb: monoclonal antibody

NIR: near infrared

PM: polymeric nanomicelle

rAAV: recombinant adeno-associated virus

scFv: single chain variable fragment

SNV: smart nano-vehicle

SUV: standard uptake values

SPION: superparamagnetic iron oxide nanoparticle

SR-A: class A scavenger receptor

TNV: theranostic nanovehicle 